\title{
FINITE ELEMENT ANALYSIS OF DEFORMATION BEHAVIOR OF STEEL HEADREST RESTRAIN PRODUCED VIA ROTARY SWAGING
}

\author{
Ludmila KRÁTKÁ, Mario MACHU゚ \\ VSB - Technical University of Ostrava, Ostrava, Czech Republic, EU, \\ ludmila.kratka@vsb.cz \\ https://doi.org/10.37904/metal.2019.689
}

\begin{abstract}
The study focused on numerical and experimental investigations of steel head restraint produced via the technology of cold rotary swaging. The analyses were carried out via finite element modelling and experimental swaging; the whole study was supplemented with 3D scanning. The experimentally swaged work-piece was scanned and eventually compared with the final product from the simulation. The results showed a good correlation of the swaged and predicted shape of the final head restraint. The numerical simulation focused especially on the distribution of equivalent imposed strain and a possible increase in temperature due to the development of deformation heat. The experimental part was supplemented with examinations of mechanical properties, and microstructure observations.
\end{abstract}

Keywords: Headrest, cold rotating swaging, deformation behaviour, numerical simulation

\section{INTRODUCTION}

Rotary swaging is, done in several ways. These methods have in common that the forging is carried out by many punches of the dies that rotate around the material. The basic division is for forging with a support pin and forging without support pin [1]. A number of scientists have been involved in the technology of rotary swaging in recent years. For example, Kalpakjian (1966) investigated changes in tube wall thickness by rotary swaging, dependent variable was material, starting pipe wall thickness, dies, angle and diameter of reduction [2]. Piela (1992), Piela (1994) and Piela (1997) analysed the rotation tapering process using the finite element method and predicted the profile of the deformation and the temperature distribution of the cross-sections [2, 3]. Seong-Joo Lim and his team (2006) studied the behaviour of a hollow blank tapered by rotary swaging without a support pin. They mainly dealt with reinforcement of alloy steel and its structural properties [2]. Qi Zhang and colleagues (2014) investigated the possibilities and behaviour of tube jointing and applications of tube narrowing using a support pin during rotary swaging. They concentrated on material flow $[4,5]$. Eric Moumi and colleagues (2014) devoted themselves to a 2D simulation of material flow and determined the shift and neutral plane dependence of the material [6]. Rotary swaging is used in the processing of metals produced by sintering of fine powders, namely, materials based on tungsten and titanium [7-9]. Other applications in the manufacture of composite materials are, for example, Cu-Al composites that are developed for the energy industry. Their advantage over the current one is that electrical conductivity is almost unchanged at reduced weight [10-12].

\section{MATERIAL AND EXPERIMENTAL METHOD}

The selected material for forging is 1.0496 steel, which chemical composition is in Table 1. The starting blank was a seamed tube that was not heat-treated. Cold rotary swaging technology was used. It is a method where the blank is motionless, and all movement is performed by dies. The dies are rotated around the tube and making approaching motion. In this method, the centre support pin is not used.

At first, the geometry of dies was created then a 3D model was created. This model was used to perform a 3D simulation of the rotary swaging of a special end of the headrest. After verification of the data from the 
simulation, the dies were made then the special end of the head restraint was manufactured. This prototype was subjected to further testing. Images were taken using the DAVID SLS 13 D scanner and were compared with the output from the simulation. Metallographic specimens were also made, where grain size was evaluated and micro-hardness values measured. Also, the most burdened areas of the dies were identified.

Table 1 Chemical composition of steel 1.0496 (wt\%)

\begin{tabular}{|c|c|c|c|c|c|c|c|c|}
\hline $\mathrm{C}$ & $\mathrm{Mn}$ & $\mathrm{Si}$ & $\mathrm{P}$ & $\mathrm{S}$ & $\mathrm{Cr}$ & $\mathrm{Ni}$ & $\mathrm{Al}$ & $\mathrm{Cu}$ \\
\hline 0.11 & 1.5 & 0.15 & 0.013 & 0.013 & 0.06 & 0.06 & 0.015 & 0.085 \\
\hline
\end{tabular}

\section{NUMERICAL SIMULATION AND HERS OUTPUTS}

The experiment uses a numerical simulation based on the FEM (Finite Element Method). Commercial software FORGE NxT 2.0 by Transvalor was used. The software is used to estimate the resilient plastic deformation behaviour of metallic materials.

The simulation of the forging is adapted so that one computational step is put together as at first part dies are drawn closer after this dies subsequently overlap to the same dimension along the perimeter of the tube. In this way, it is achieved that the material is symmetrically moulded and at the same time carry out the requirements for form precision. The simulation outputs are evaluated from two views. The first is how the material flows and how perfectly fills the die cavity and the shape accuracy of the resulting profile. As others are evaluated, the temperature of the material during moulding, the applied deformation, the stress intensity.

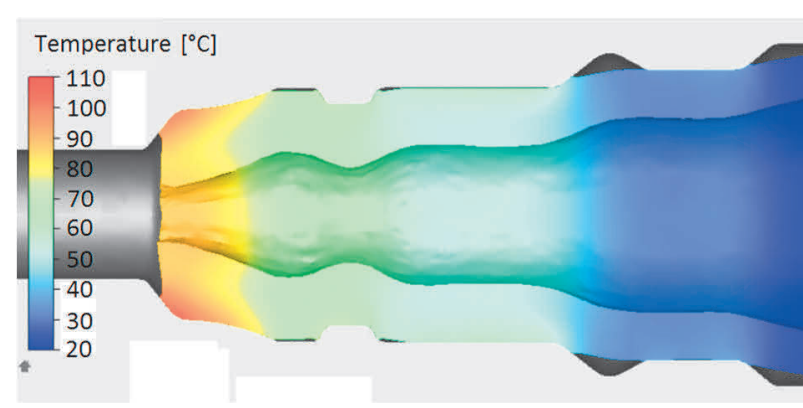

Figure 1 Temperature

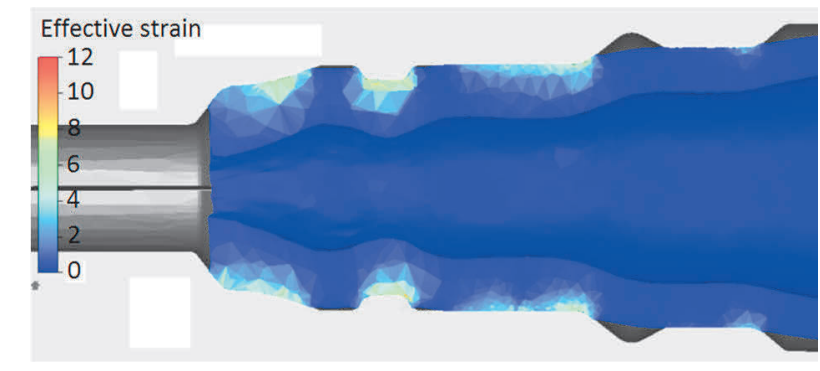

Figure 3 Effective strain

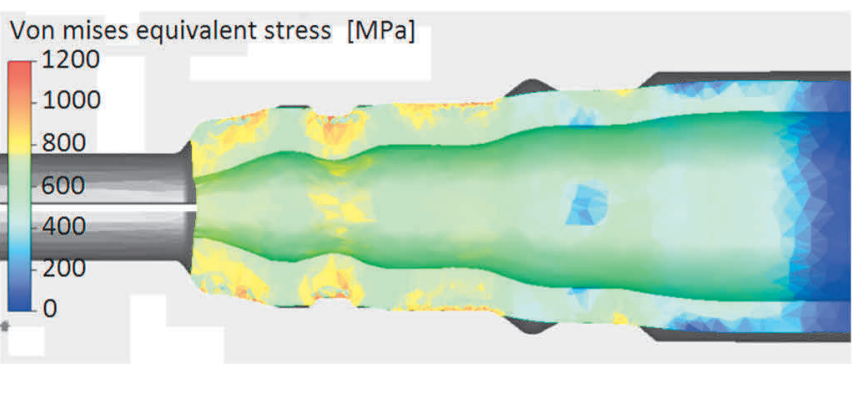

Figure 2 Von Mises equivalent stress

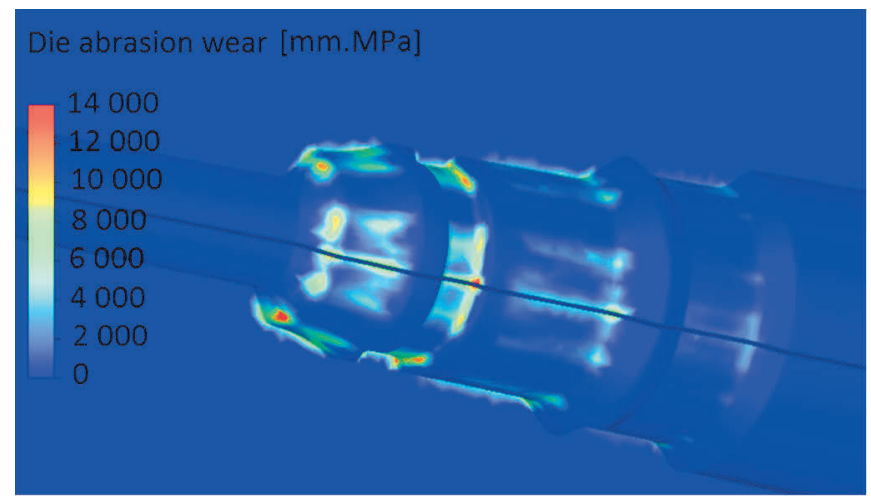

Figure 4 Die abrasion wear

Figure 1 shows the temperature field during the simulation. It is evident that the material heats most in the places where the material is most deformed. The highest measured temperature is $112{ }^{\circ} \mathrm{C}$. Figure 2 shows von Mises equivalent stress when dies are drawn closer. In this case, we get values ranging from $400 \mathrm{MPa}$ to $1150 \mathrm{MPa}$. In other turns, we do not get these high values. Figure 3 shows the Effective strain. The 
deformation does not intersect the whole cross-section. It is caused by the fact that the material can flow freely in the direction both of increasing the thickness of the wall and in the forward direction. The simulation evaluates the effect of hardware on tool wear. Figure $\mathbf{4}$ shows the areas most frequently in contact, and we can assume that the tools will wear the most in these places.

\section{EXPERIMENT AND TESTING}

The next stage was a real implementation. Initially, dies were manufactured according to the proposed profile, then a prototype of the headrest for the automobile support was made (Figure 5). Analysis of the shape was taken on the DAVID SLS $13 \mathrm{D}$ scanner, microstructure analysis with grain size determination and microhardness measurement were performed on real samples.

Figure 6 is a scanned end of a real-walled tube with a 3D tube model, which is the output of a 3D simulation of fittings. In important parts, real forging and model match tolerances, that is areas marked with green. They do not match in red areas because they are wrinkled at these locations. In these areas, tolerance has been slightly exceeded, but this does not have a decisive impact on the overall assessment.

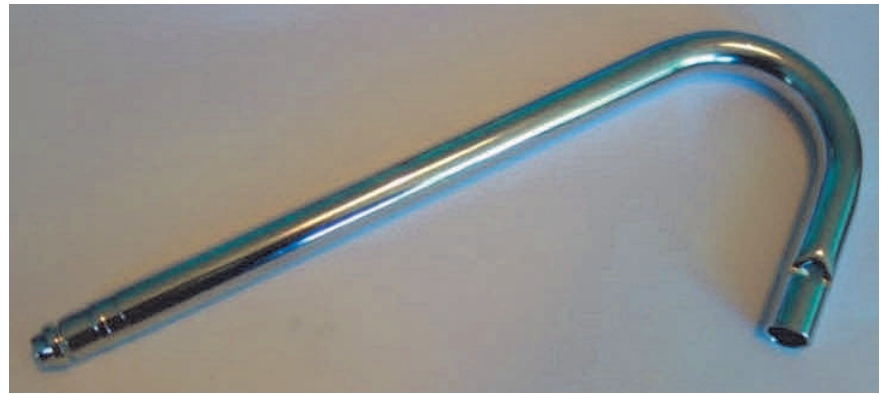

Figure 5 Prototype of head support

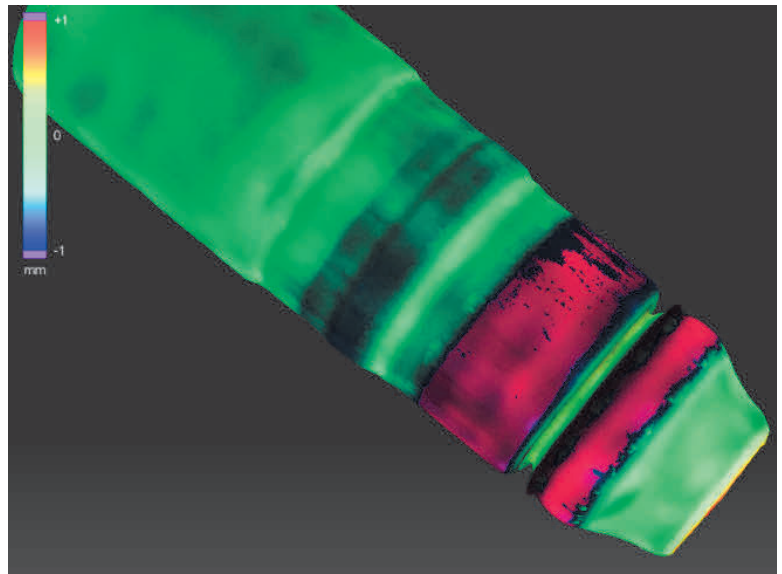

Figure 6 Comparison of 3D scan and model

On selected microstructures (Figure 8 and 9) we see a ferritic-pearlitic structure with grain boundaries displayed. For sample $A$, we see a less deformed structure showing linearity, and we can see that grain size is larger than for sample 4B. On sample 4B, we also observe the linearity in the material, and there is also a good flow of material.

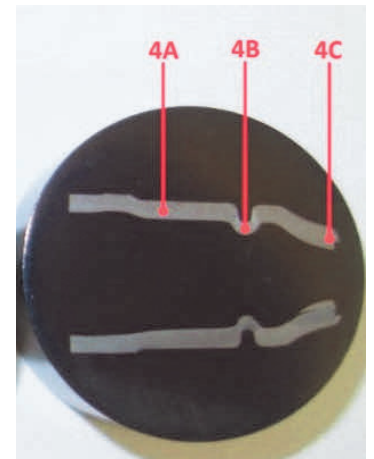

Figure 7 Examined areas

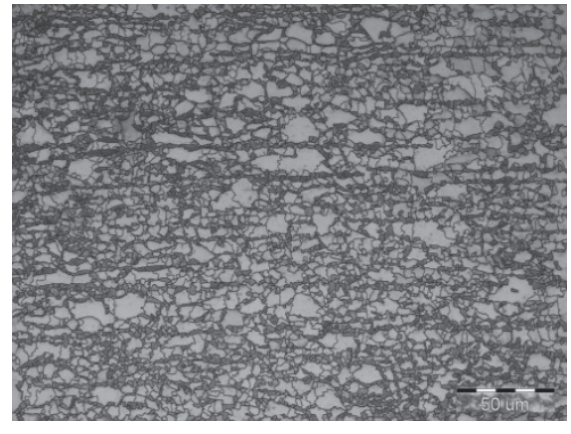

Figure 8 Area $4 \mathrm{~A}$

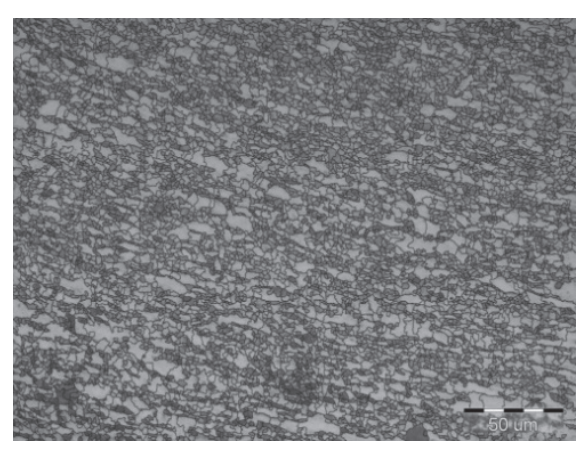

Figure 9 Area 4B

Measurement of micro-hardness took place in the same areas as observation of structural states (Figure 7). The measurement was chosen in such a way that the micro-hardness was evaluated in five consecutive 
locations in order to map the entire thickness of the wall. The graph (Figure 10) shows the hardness at the average value, indicating that the greatest reinforcement occurs at the point of the groove. From this phenomenon, we assume that the largest deformation was inserted at this point.

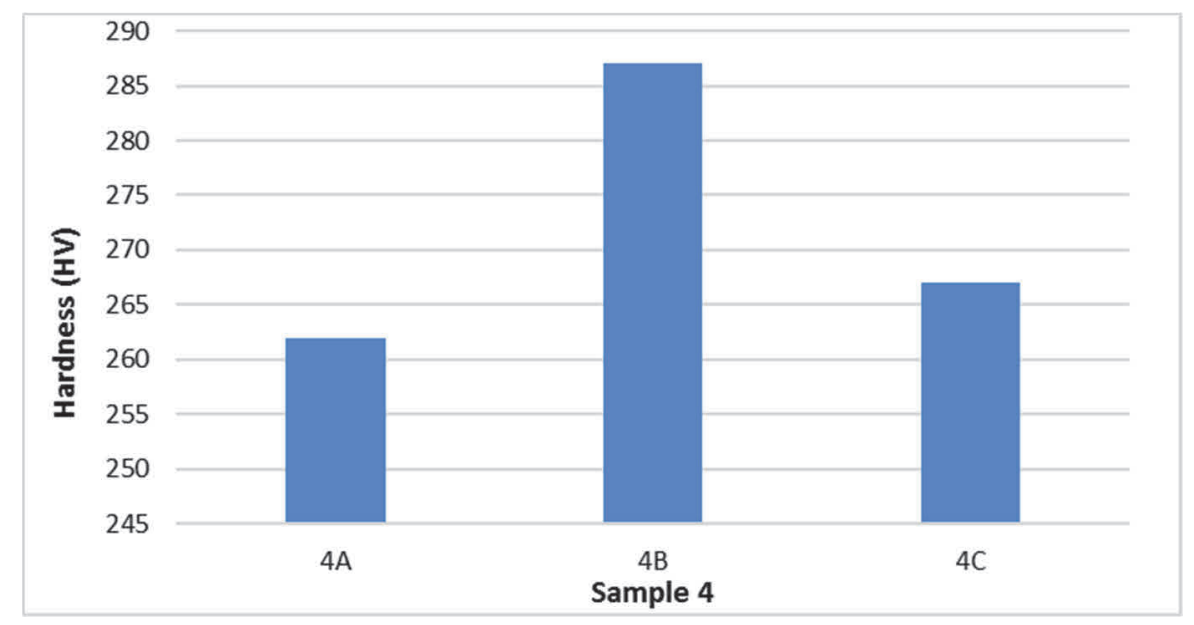

Figure 10 Average hardness

\section{CONCLUSION}

- $\quad$ The design of the dies complies with the requirements that led to the production of real dies. The production was preceded by finite element simulation processing, which results from the evaluation of the waveforms of the selected deformation parameters, that the dippers meet the geometrical precision of the shape of the particular end of the head restraint.

- $\quad$ Simulation of rotary swaging shows that wall thickness is increased during moulding. The highest increase is in the front where the tube diameter is the most pressed. There is nothing to prevent the increasing wall thickness because it is not forging on the mandrel. The flow of material moves along the path of the least resistance, so it does not tend to move forward significantly. The shape of the forged special end of the headrest does not fill the geometry of the dies perfectly, which causes the existence of elastic deformations.

- Metallographic analysis of samples shows that with increasing deformation ferritic-pearlitic grains are refined. A single-sided texture is created due to the grain being drawn in one direction, in this case, the linearity of the structure. From the microhardness measurement, the hardness increases with increasing deformation.

- $\quad$ By comparing a 3D scan of a real-looking special end of the headrest and a 3D model of a tube that is the output of the numerical simulation, the profile of the real-purpose special head end of the headrest corresponds to important areas of the 3D model.

\section{ACKNOWLEDGEMENTS}

\section{The research was supported by the grant projects SP2019/86 (MŠMT ČR).}

\section{REFERENCES}

[1] KRÁTKÁ, Ludmila. Design and analysis of the manufacture of specialized automobile head restraints. Ostrava, 2018. Diploma thesis. VSB-Technical University of Ostrava. Thesis Supervisor Radim Kocich. 
[2] LIM, Seong-Joo, CHOI, Ho-Joon and LEE, Chi-Hwan. Forming characteristics of the tubular product through the rotary swaging process. Journal of Materials Processing Technology [online]. 2009. vol. 209, no. 1, pp. 283-288. Available from: https://www.sciencedirect.com/science/article/pii/ S0924013608001167

[3] PIELA, Antoni. Analysis of Metal flow in Swaging - Numerical modeling and experimental verification. International Journal of Mechanical Sciences [online]. 1997. vol. 39, no. 2, pp. 221-231. Available from: https://www.sciencedirect.com/science/article/pii/0020740396000562

[4] ZHANG, Qi, JIN, Kaiqiang and MU, Dong. Tube / tube joining technology using rotary swaging forming method. Journal of Materials Processing Technology [online]. 2014. vol. 214, no. 10, pp. 2085-2094. Available from: https://www.sciencedirect.com/science/article/pii/S0924013614000430

[5] ZHANG, Qi, JIN, Kaiqiang, MU, Dong, MA, Pengju and TIAN, Jie. Rotary swaging forming process of tube workpieces. Procedia Engineering [online]. 2014. vol. 81, pp. 2336-2341 Available from: https://www.sciencedirect.com/science/article/pii/S1877705814016099

[6] MOUMI, Eric, ISHKINA, Svetlana, KUHFUSS, Bernd, HOCHRAINERA, Thomas, STRUSS, Adrian and HUNKEL, Martin. 2D-simulation of material flow during feed rotation using finite element method. Procedia Engineering [online]. 2014. vol. 81, pp. 2342-2347 Available from: https://www.sciencedirect.com/science/article/pii/S1877705814016105

[7] KOCICH, Radim, KUNČICKÁ, Lenka, DOHNALÍK, Daniel, MACHÁČKOVÁ, Adéla a ŠOFER, Michal. Cold rotary swaging of a tungsten heavy alloy: Numerical and experimental investigations. Int. Journal of Refractory Metals and Hard Materials61 [online]. 2016. vol. 61, pp. 264-272. Available from: https://www.sciencedirect.com/science/article/pii/S0263436816304267]

[8] KUNČICKÁ, Lenka, KOCICH, Radim, HERVOCHES, Charles a MACHÁČKOVÁ, Adéla. Study of structure and residual stresses in cold rotary swaged tungsten heavy alloy. Materials Science \& Engineering A [online]. 2017. vol. 704, pp. 25-31. Available from: https://www.sciencedirect.com/science/article/pii/S0921509317310006

[9] HASSELBRUCH, Henning, HERRMANN, Marius, MEHNER, Andreas, KUHFUSS, Bernd a ZOCH, HansWerner. Incremental dry forging - Interaction of W-DLC coatings and surface structures for rotary swaging tools. Procedia Engineering [online]. 2017. vol. 8, pp. 541-548. Available from: https://www.sciencedirect.com/science/article/pii/S2351978917300756

[10] KOCICH, Radim, KUNČICKÁ, Lenka, MACHÁČKOVÁ, Adéla a ŠOFER, Michal. Improvement of mechanical and electrical properties of rotary swaged Al-Cu clad composites. Materials and Design [online]. 2017. vol. 123, pp. 137-146. Available from: https://www.sciencedirect.com/science/ article/pii/S0264127517302964

[11] KOCICH, Radim, KUNČICKÁ, Lenka, KRÁL, Petr a STRUNZ, Pavel. Characterization of innovative rotary swaged Cu-Al clad composite wire conductors. Materials and Design [online]. 2018. vol. 160, pp. 828-835. Available from: https://www.sciencedirect.com/science/article/pii/S0264127518307822

[12] KUNČICKÁ, Lenka, KOCICH, Radim, DVOŘÁK, Karel a MACHÁČKOVÁ, Adéla. Rotary swaged laminated Cu-AI composites: Effect of structure on residual stress and mechanical and electric properties. Materials Science \& Engineering $A$ [online]. 2019. vol. 742, pp. 743-750. Available from: https://www.sciencedirect.com/science/article/pii/S0921509318315430 